\title{
Development and calibration of a dietary nitrate and nitrite database in the NIH-AARP Diet and Health Study
}

\author{
Maki Inove-Choi ${ }^{1,2}$, Mandeep K Virk-Baker ${ }^{3}$, Briseis Aschebrook-Kilfoy ${ }^{1,4}$, Amanda J Cross ${ }^{5}$, \\ Amy F Subar ${ }^{6}$, Frances E Thompson ${ }^{6}$, Rashmi Sinha ${ }^{7}$ and Mary H Ward ${ }^{1, *}$ \\ 'Occupational and Environmental Epidemiology Branch, Division of Cancer Epidemiology \& Genetics, National \\ Cancer Institute, National Institutes of Health, Department of Health and Human Services, 9609 Medical Center \\ Drive, 6E314, Rockville, MD 20850, USA: ${ }^{2}$ National Institute on Minority Health and Health Disparities, National \\ Institutes of Health, Department of Health and Human Services, Bethesda, MD, USA: ${ }^{3}$ Cancer Prevention Fellowship \\ Program, Division of Cancer Prevention, National Cancer Institute, National Institutes of Health, Rockville, MD, USA: \\ ${ }^{4}$ Division of Biologic Sciences, Department of Public Health Sciences, University of Chicago, Chicago, IL, USA: \\ ${ }^{5}$ Department of Epidemiology and Biostatistics, School of Public Health, Imperial College London, London, UK: \\ ${ }^{6}$ Epidemiology and Genomics Research Program, Risk Factor Assessment Branch, Division of Cancer Control and \\ Population Sciences, National Cancer Institute, Rockville, MD, USA: ${ }^{7}$ Nutritional Epidemiology Branch, Division of \\ Cancer Epidemiology \& Genetics, National Cancer Institute, National Institutes of Health, Department of Health and \\ Human Services, Rockville, MD, USA
}

Submitted 27 April 2015: Final revision received 28 September 2015: Accepted 2 November 2015: First published online 2 December 2015

\begin{abstract}
Objective: Nitrate and nitrite are probable human carcinogens when ingested under conditions that increase the formation of $\mathrm{N}$-nitroso compounds. There have been limited efforts to develop US databases of dietary nitrate and nitrite for standard FFQ. Here we describe the development of a dietary nitrate and nitrite database and its calibration.

Design: We analysed data from a calibration study of 1942 members of the NIH-AARP (NIH-AARP, National Institutes of Health-AARP) Diet and Health Study who reported all foods and beverages consumed on the preceding day in two non-consecutive $24 \mathrm{~h}$ dietary recalls (24HR) and completed an FFQ. Based on a literature review, we developed a database of nitrate and nitrite contents for foods reported on these $24 \mathrm{HR}$ and for food category line items on the FFQ. We calculated daily nitrate and nitrite intakes for both instruments, and used a measurement error model to compute correlation coefficients and attenuation factors for the FFQ-based intake estimates using 24HR-based values as reference data.

Results: FFQ-based median nitrate intake was 68.9 and $74.1 \mathrm{mg} / \mathrm{d}$, and nitrite intake was 1.3 and $1.0 \mathrm{mg} / \mathrm{d}$, in men and women, respectively. These values were similar to $24 \mathrm{HR}$-based intake estimates. Energy-adjusted correlation coefficients between FFQ- and 24HR-based values for men and women respectively were 0.59 and 0.57 for nitrate and 0.59 and 0.58 for nitrite; energy-adjusted attenuation factors were 0.59 and 0.57 for nitrate and 0.47 and 0.38 for nitrite.

Conclusions: The performance of the FFQ in assessing dietary nitrate and nitrite intakes is comparable to that for many other macro- and micronutrients.
\end{abstract}

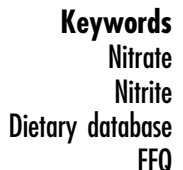

FFQ
Nitrate is ingested from dietary sources and drinking water. Vegetables, especially dark green leafy and certain root vegetables, are usually the primary source when levels of nitrate in drinking water are below $50 \mathrm{mg} / \mathrm{l}$, the regulatory limit in many countries ${ }^{(1)}$. Once ingested, nitrate can be reduced to nitrite by the oral bacteria. In the gastrointestinal tract, especially in the stomach, nitrite further reacts with amines and amides to form $N$-nitroso compounds (NOC), known animal carcinogens ${ }^{(2)}$ and probable human carcinogens ${ }^{(3-5)}$. Nitrate and nitrite also are used as food additives in processed meats for curing as well as to enhance colour and flavour. Dietary intake of nitrite comes primarily from the consumption of cured meats and fish, baked goods and cereal products. As such, elevated levels of endogenously formed nitrite from nitrate and higher intake of dietary nitrite may increase endogenous NOC formation and thus individuals' risk for cancer. 
Vegetables contain nutrients that can inhibit endogenous nitrosation, such as vitamin $\mathrm{C}$ and polyphenols. Although nitrate from both vegetables and drinking water undergoes reduction to nitrite in the body, nitrate from vegetables probably results in less endogenous NOC formation because of the presence of inhibitors of nitrosation ${ }^{(6)}$. Higher nitrite intake from processed meats has been shown to result in elevated NOC formation in animal studies ${ }^{(4,7)}$. The combination of higher intake of nitrate with an amine source and low intake of vitamin $\mathrm{C}$ has been shown to increase the endogenous formation of NOC in human biomonitoring studies $^{(5,8,9)}$. However, to date, only a limited number of prospective cohort studies have evaluated overall dietary nitrate and nitrite intakes ${ }^{(10-17)}$ or nitrite intake from animal foods or processed meats ${ }^{(14,15,18-22)}$ in relation to risk of various cancers, and results are inconclusive.

An extensive body of literature exists on nitrate and nitrite contents in foods and several large databases have been developed for European epidemiological studies in the UK, France, the Netherlands and Spain ${ }^{(23-26)}$. To date, there have been limited efforts to develop US databases of nitrate and nitrite contents in foods and by extension for FFQ ${ }^{(27-29)}$. Here, we describe a dietary nitrate and nitrite database developed for an early version of the National Cancer Institute (NCI) Diet History Questionnaire (DHQ), which was used to assess dietary and supplement intakes in the NIH-AARP (National Institutes of Health-AARP) Diet and Health Study. We analysed data from a calibration study to evaluate the performance of the DHQ for estimated nitrate and nitrite intakes using intakes from $24 \mathrm{~h}$ dietary recalls (24HR) as reference data.

\section{Methods}

\section{The NIH-AARP Diet and Health Study}

From 1995 through 1996, a baseline questionnaire was mailed to 3.5 million current AARP members aged 50-71 years residing in California, Florida, Pennsylvania, New Jersey, North Carolina and Louisiana, or two metropolitan areas (Atlanta, Georgia and Detroit, Michigan) ${ }^{(30)}$. Usual dietary intake and use of dietary supplements were assessed with the NCI DHQ (described below). Among 567169 persons who had a satisfactory baseline questionnaire, we excluded 76975 individuals as described previously ${ }^{(30,31)}$. Major reasons for exclusion included prior diagnosis of cancer (except for non-melanoma skin cancer; $n$ 51193), questionnaires completed by proxies ( $n$ 15 760) and extreme values for total energy intake (beyond twice the interquartile range of Box-Cox log-transformed intake; total $n$ 4382). The final cohort for assessment of dietary nitrate and nitrite intakes included 490194 participants (292125 men, 198069 women).

\section{Dietary intake data collection}

Dietary intake during the previous 12 months was assessed at baseline using an early version of the NCI DHQ, an FFQ including the frequency of consumption and corresponding portion sizes of 124 food items. The food items, portion sizes, nutrient database and pyramid food servings database were constructed using methods developed by Subar et al. ${ }^{(32)}$ with national dietary data from the US Department of Agriculture's 1994-1996 Continuing Survey of Food Intakes by Individuals (CSFII) ${ }^{(33)}$. Participants were queried about their frequency of intake in ten categories ranging from 'never' to ' $\geq 2$ times per day' for foods and from 'never' to ' $\geq 6$ times per day' for beverages. Each food item was accompanied by three portion size categories established based on sex- and age group-specific portion sizes from the $\mathrm{CSFII}^{(32)}$. Use of selected dietary supplements was also assessed.

The performance of the NCI DHQ in the NIH-AARP Diet and Health Study population was previously evaluated for major macro- and micronutrients ${ }^{(34)}$. Energy-adjusted correlations between FFQ- and 24HR-based intake estimates ranged from 0.40 (vitamin E) to 0.76 (saturated fat) and from 0.36 (vitamin $\mathrm{E}$ ) to 0.70 (vitamin $\mathrm{B}_{6}$ ) among men and women, respectively. Energy-adjusted attenuation factors ranged from 0.26 (protein) to 0.68 (saturated fat) and from 0.24 (vitamin E) to 0.62 (vitamin $\mathrm{B}_{6}$ ) among men and women, respectively.

\section{Estimation of nitrate and nitrite concentrations in foods}

We estimated the nitrate and nitrite contents of the food groups asked on the NCI DHQ based on a literature review of published studies and reports. We used twenty-six studies or reports published between 1967 and 2008 ${ }^{(1,23,25,26,35-56)}$ (see online supplementary material, Table S1). This range of publication years was chosen based on the time frame of our dietary intake assessment, particularly because the allowed levels of added nitrate and nitrite in processed meats have changed in past decades. First, we included studies with published values for nitrate or nitrite focusing on food products in the USA and Canada because nitrate and nitrite levels in some foods (e.g. processed meats, cheeses) can vary internationally ${ }^{(56,57)}$. Nitrate and nitrite levels for most commonly consumed food items were identified in literature in the USA or Canada. However, because of limited US or Canadian data on nitrate and nitrite values for some other food items, many of which were ingredients included in recipes for mixed dishes, we expanded our literature search to studies performed in other countries. Information regarding cooking method, number of samples analysed, ranges of values, means and standard deviations was abstracted, if available. If multiple studies were available for a particular food/cooking method combination, we calculated the average nitrate or nitrite level, weighted by the number of samples analysed in each study. For vegetable items specified as cooked in the FFQ where only a raw value was available in the literature, the changes in nitrate through cooking were estimated because the process of cooking 
typically lowers nitrate concentrations. For example, at least $50 \%$ of nitrate in vegetables can be removed by cooking in water ${ }^{(58)}$.

Nitrate and nitrite composition of each FFQ line item (e.g. tomatoes) was computed by weighting the food-specific values by age group- and sex-specific intake amounts found in the CSFII and summing over all foods defined in the FFQ line item. For example, we used composition estimates for raw, canned and cooked tomatoes to derive a weighted composition estimate for the FFQ line item 'tomato'. Nitrate and nitrite values were assigned to FFQ mixed dish food items (e.g. vegetable soup, beef stew, chicken pot pie, various salads, sandwiches, meatloaf) using standardized recipes. The values assigned to these mixed dishes were a weighted average of the nitrate and nitrite contents of the foods in the recipe. For a few mixed dishes, values for a food in the recipe were not available in the literature (e.g. water chestnut) and we substituted a value for a food we thought might have similar nitrate and nitrite levels (e.g. white potato).

\section{Dietary nitrate and nitrite intakes in the NIH-AARP Diet and Health Study}

For each cohort participant, daily intake estimates of nitrate and nitrite were calculated by multiplying the nitrate and nitrite composition of each FFQ food item by the reported frequency of consumption and portion size, and summing values across all food items. The average daily intake level was calculated for the entire cohort overall and for men and women separately. Nitrate and nitrite intakes from plant, animal and processed meat sources were computed separately. The percentage contribution of each FFQ food item to total daily nitrate and nitrite intakes was also calculated.

\section{Measurement of nitrate and nitrite in processed meat products}

We used a database of nitrate and nitrite amounts that was previously developed for ten types of processed meat representing $90 \%$ of the processed meats consumed in the USA, according to the CSFII 1994-1996(59,60), to evaluate whether our daily intake estimates of nitrate and nitrite from processed meats based on a literature review are comparable to intake estimates based on the measurement-based database for processed meat products. For each of ten meat types, we measured the nitrate, nitrite and multiple NOC composition from composites prepared from major brand name meats that were available from grocery stores in the Blacksburg, Virginia area in 2004. If major brand name products were not available, a local/regional or store brand product was substituted. We computed nitrate and nitrite intake estimates from processed meat based on these measured nitrate and nitrite amounts multiplied by reported daily intakes in the FFQ in the calibration study population.
As previously described, NOC were not detected in any processed meats ${ }^{(59)}$.

\section{Calibration study}

A calibration study for dietary nitrate and nitrite intake estimates from the FFQ was conducted in the subset of cohort members previously described in the calibration analyses of macro- and micronutrients ${ }^{(34)}$. Briefly, from 38691 individuals who completed the baseline FFQ and were eligible for selection into the calibration study, 6150 individuals were randomly selected by a combination of fixed and random stratified sampling to ensure approximate representation by sex and to enhance minority inclusion and increase heterogeneity of dietary intakes of fat, fruits and vegetables, fibre and red meat. Participants with extreme intakes $(10 \%$ in each of the lowest and highest intake categories) on any of these four dietary variables were sampled at a higher rate than others. Telephone numbers were obtained for 3901 individuals and recruitment was attempted by telephone calls for 3647; of these, 2923 individuals were reached. After excluding 128 individuals who could not be located, had language problems or were too ill to participate, 2795 individuals were invited to participate in the calibration study and 2053 completed the first $24 \mathrm{HR}$. Of these respondents, 1445 individuals also completed the second $24 \mathrm{HR}$. The two $24 \mathrm{HR}$ were both unannounced ahead of time and well separated in time from March to September 1996, mostly within a year from the FFQ completion. In the $24 \mathrm{HR}$ interviews, participants were asked to report all foods and beverages consumed on the day preceding the interview. Trained interviewers used a Food Probe List containing standardized probes specific to foods in over 100 food categories. Data were coded using the Food Intake Analysis System (FIAS), version 2.3, developed at the University of Texas. The $24 \mathrm{HR}$ reports with extremely high values for fat, total energy, total fruit and vegetable intakes were examined, and coding errors were corrected accordingly if errors were found.

From the 2053 respondents to the first $24 \mathrm{HR}$, we excluded 100 individuals who met exclusion criteria consistent with the overall baseline cohort including subsequent drop-outs ( $n$ 78), registry-ascertained history of cancer $(n 9)$ and deathonly reports of cancer ( $n$ 13). As a result, 1953 individuals (987 men and 966 women) who completed the baseline FFQ and at least the first $24 \mathrm{HR}$ remained in the calibration study. For each day of the $24 \mathrm{HR}$, we assigned food-specific nitrate and nitrite values to reported food items and computed daily nitrate and nitrite intakes by multiplying the nitrate and nitrite contents of each food item by the reported amounts of intake, and summing values across all food items. We performed an additional literature review to find nitrate and nitrite values for food items that were not included in the FFQ. Nitrate and nitrite intake averages over the two days were computed for each calibration study participant. For the sixty-three individuals who did not complete a second $24 \mathrm{HR}$, 
only the first $24 \mathrm{HR}$ was used in measurement error modeling (see below).

\section{Statistical analysis}

We determined the average percentage contribution to nitrate and nitrite intakes from each food item for FFQ and $24 \mathrm{HR}$ data for men and women separately. We evaluated the performance of the FFQ by determining two parameters: the Pearson correlation coefficient $\left(r_{\mathrm{Q}, \mathrm{T}}\right)$ and the attenuation factor $\left(\lambda_{\mathrm{Q}}\right)$ for FFQ-reported intakes (Q) using 24HR-based values $(\mathrm{T})$ as the reference 'true intake ${ }^{\text {(34) }}$. We estimated the correlation and attenuation factor by fitting a measurement error model for the FFQ and 24HR measurements suggested by Kipnis et al. to all participants of the calibration study using the maximum likelihood approach ${ }^{(61)}$. An assumption of this approach is that the error in the reference measure (24HR data) is independent of the true intake and independent of the error in FFQ-based data ${ }^{(61)}$

The correlation $r_{\mathrm{Q}, \mathrm{T}}$ determines the extent of misclassification in the FFQ-based intake (as quantiles). The attenuation factor is a slope in the regression of true intake $v$. FFQ-reported intake. In a univariate model for the association between dietary exposures and risk of disease, the observed relative risk (RR) for a given change in the dietary exposure is equal to the true RR raised to power $\lambda_{\mathrm{Q}}$. In studies evaluating dietary exposures, $\lambda_{\mathrm{Q}}$ is usually confined between 0 and 1 , therefore attenuating a true RR (biasing a RR towards 1). An attenuation factor close to 0 indicates severe attenuation and an attenuation factor close to 1 indicates very little attenuation. For example, if $\lambda_{\mathrm{Q}}=0 \cdot 5$, a true RR of 2 would be observed as $2^{0.5}=1.41$ and if $\lambda_{\mathrm{Q}}=0.1$ as $2^{0.1}=1 \cdot 07$.

Because distributions of nitrate and nitrite intakes were highly skewed, the measurement error model was fitted after excluding extreme outliers and transforming intake values to approximate normality using a transformation within the Box-Cox transformation family ${ }^{(34)}$. Box-Cox transformation also aimed to improve 24HR-based intake as a reference instrument by making the random error more homoscedastic. After excluding outliers, 1942 individuals (984 men and 958 women) were included in the analysis. We computed correlation and attenuation factors for total nitrate and nitrite intakes and nitrite from animal and plant sources separately in unadjusted and adjusted models using the residual energy adjustment method $^{(62)}$. We did not separate nitrate intake into animal and plant sources because, on average, about $94 \%$ of dietary nitrate was derived from plant foods. We also computed correlations of estimated daily nitrate and nitrite intakes from processed meat based on a literature review with the estimates based on measured nitrate and nitrite concentrations in processed meat products.

\section{Results}

The estimated nitrate and nitrite composition (mg/100 $\mathrm{g}$ food weight) in the FFQ line items are presented in the online supplementary material, Table $\mathrm{S} 2$. Nitrate levels ranged from 0 to $180.0 \mathrm{mg} / 100 \mathrm{~g}$ with the highest concentrations in certain vegetables. Raw spinach and lettuce contained the highest amounts of nitrate $(180 \mathrm{mg} / 100 \mathrm{~g}$ and $170 \mathrm{mg} / 100 \mathrm{~g}$, respectively), whereas sweets, nuts, fats and oils contained only trace amounts. Nitrite contents ranged from 0 to $7 \cdot 2 \mathrm{mg} / 100 \mathrm{~g}$ with the highest concentrations in processed meats. FFQ food items including ham (not luncheon) and cold cuts/sausage/hot dogs had the highest nitrite concentrations $(7 \cdot 2$ and $2.4 \mathrm{mg} / 100 \mathrm{~g}$, respectively). Much smaller amounts of nitrite $(0-0.7 \mathrm{mg} / 100 \mathrm{~g})$ were found in cottage cheese, fat-rich foods such as butter or margarine, and various fruit juices.

As reported previously, the calibration sub-cohort represented the overall baseline cohort with regard to selected demographic (e.g. age, race/ethnicity, educational level), lifestyle (e.g. smoking, physical activity, diet, BMI, hormone use), self-reported health status and family history of cancer ${ }^{(34)}$. Although stratified sampling was implemented to select the calibration sub-cohort to increase heterogeneity of dietary intake distributions, the median values and distributions of the selected dietary intakes (total energy, total fat, carbohydrate, protein, and fruit and vegetables) were similar between the calibration sub-cohort and the overall cohort ${ }^{(34)}$.

Based on FFQ data for the entire cohort, average daily nitrate intake was $85.3 \mathrm{mg} / \mathrm{d}$ (men) and $91.6 \mathrm{mg} / \mathrm{d}$ (women). Average daily nitrite intake was $1.3 \mathrm{mg} / \mathrm{d}$ (men) and $1.1 \mathrm{mg} / \mathrm{d}$ (women). Average intake of nitrate from plant sources was $79.8 \mathrm{mg} / \mathrm{d}$ (men) and $86.9 \mathrm{mg} / \mathrm{d}$ (women), representing $94-95 \%$ of total dietary nitrate intake on average; whereas average intake of nitrite from plant sources was $0.8 \mathrm{mg} / \mathrm{d}$ (men) and $0.7 \mathrm{mg} / \mathrm{d}$ (women), representing $64-70 \%$ of total dietary nitrite intake on average.

From the calibration study, the median and interquartile range of nitrate and nitrite intakes derived from FFQ and 24HR data are presented separately for men and women in Table 1. Overall, estimated median nitrate and nitrite intakes based on the FFQ and 24HR were similar. When comparing nitrate and nitrite intakes from the first and second $24 \mathrm{HR}$, higher nitrate intake was reported in the second $24 \mathrm{HR}$ especially among women. Nitrite intake values (total and from animal and plant sources) were nearly identical between the two $24 \mathrm{HR}$.

Based on the FFQ in the calibration study, lettuce was the top contributor to total nitrate intake in both men $(32.5 \%)$ and women $(35.0 \%)$, followed by other vegetables such as spinach and other greens (raw and cooked), broccoli, string beans and coleslaw/cabbage/ sauerkraut (Table 2). Other top contributors to dietary nitrate intake included potatoes (white), bananas, cantaloupe and other melons. The $24 \mathrm{HR}$ data showed similar food items among the top twenty contributors to dietary nitrate intake. However, certain food items that were not listed in the FFQ were among the top twenty 
Table 1 Estimated median and interquartile range (IQR) of daily intakes of nitrate and nitrite $(\mathrm{mg} / \mathrm{d})$ by sex for the FFQ and the $24 \mathrm{~h}$ dietary recalls $(24 \mathrm{HR})$ in the calibration sub-study: NIH-AARP Diet and Health Study, 1995-1996

\begin{tabular}{|c|c|c|c|c|c|c|}
\hline & & & \multicolumn{4}{|c|}{ 24HR } \\
\hline & \multicolumn{2}{|c|}{ FFQ } & \multicolumn{2}{|c|}{ First } & \multicolumn{2}{|c|}{ Second } \\
\hline & Mean & IQR & Mean & IQR & Mean & IQR \\
\hline \multicolumn{7}{|l|}{ Men } \\
\hline$n$ & \multicolumn{2}{|c|}{984} & \multicolumn{2}{|c|}{984} & \multicolumn{2}{|c|}{953} \\
\hline Nitrate (total) & 68.9 & $42 \cdot 4-106 \cdot 8$ & $65 \cdot 0$ & $30 \cdot 3-158 \cdot 0$ & 68.4 & $30 \cdot 6-168 \cdot 2$ \\
\hline \multicolumn{7}{|l|}{ Nitrite } \\
\hline Total & 1.3 & $0.9-1.7$ & 1.4 & $0.9-2.0$ & 1.4 & $0.9-2.0$ \\
\hline Plant sources & 0.8 & $0.5-1.1$ & 0.9 & $0.6-1 \cdot 3$ & 0.9 & $0.6-1.3$ \\
\hline Animal sources & 0.4 & $0.3-0.6$ & 0.4 & $0.2-0.8$ & 0.4 & $0.2-0.7$ \\
\hline \multicolumn{7}{|l|}{ Women } \\
\hline$n$ & \multicolumn{2}{|c|}{958} & \multicolumn{2}{|c|}{958} & \multicolumn{2}{|c|}{926} \\
\hline Nitrate (total) & $74 \cdot 1$ & $47 \cdot 0-116 \cdot 4$ & $62 \cdot 4$ & $23 \cdot 5-144 \cdot 2$ & 74.8 & $29 \cdot 0-149 \cdot 1$ \\
\hline \multicolumn{7}{|l|}{ Nitrite } \\
\hline Total & 1.0 & $0.7-1 \cdot 3$ & 1.0 & $0.7-1.4$ & $1 \cdot 0$ & $0.7-1.4$ \\
\hline Plant sources & 0.7 & $0.5-0.9$ & 0.7 & $0.4-1.0$ & 0.7 & $0.4-1.0$ \\
\hline Animal sources & 0.3 & $0.2-0.4$ & 0.2 & $0.1-0.4$ & 0.2 & $0.2-0.4$ \\
\hline
\end{tabular}

$\mathrm{NIH}-\mathrm{AARP}$, National Institutes of Health-AARP.

contributors to dietary nitrate in the $24 \mathrm{HR}$. These food items included avocado/guacamole (17th in men and 15 th in women) and pickled vegetables/fruits (16th in men and 12 th in women). Food items identified as top contributors to total nitrite intake were similar in FFQ- and 24HR-based data (Table 3). Based on FFQ-reported intake in the calibration study, a top contributor to nitrite in men was cold cuts ( $8.6 \%)$, followed by bread, pasta, rice/grains and hot breakfast cereal. In women, similar food items were identified as top contributors to total nitrite intake. Processed meats such as ham and hot dogs were among top twenty contributors to total nitrite intake in both men and women based on both the FFQ and the $24 \mathrm{HR}$. When we compared the FFQ-based nitrite intake estimate from processed meats using the database we developed from our literature review with daily intake estimates using measured values in composite samples, the two estimtes were highly correlated $(r=0 \cdot 99)$. Nitrate intake estimates from processed meats based on our database from a literature review and based on measured values were also highly correlated $(r=0 \cdot 95)$.

Estimated unadjusted correlation coefficients between the FFQ-reported nitrate intake and the true intake based on the 24HR were moderate both in men $(r=0.53)$ and women $(r=0.48$; Table 4$)$. When adjusted for energy intake, the correlations became slightly higher, especially in women $(r=0.57)$. Attenuation factors for dietary nitrate intake were 0.49 in men and 0.46 in women. Again, adjusting for energy intake improved attenuation factors in both men $(r=0.59)$ and women $(r=0.57)$. Compared with total nitrate, lower unadjusted correlation coefficients for total nitrite intake were observed in men $(r=0.45)$ and women $(r=0 \cdot 37)$. However, energy-adjusted correlation coefficients for nitrite were similar to those for dietary nitrate intake $(r=0.59$ and 0.58 for men and women, respectively). Similarly, attenuation factors for total nitrite intake improved considerably after adjusting for energy intake ( 0.47 in men and 0.38 in women); however, attenuation in FFQ-based nitrite intake was more severe than attenuation in FFQ-reported nitrate intake. Similar correlation and attenuation factors were observed for nitrite from animal and plant sources, both of which were slightly higher than those for total nitrite intake.

\section{Discussion}

In the NIH-AARP Diet and Health Study, we found that total dietary nitrate intake was mostly from green leafy vegetable consumption, while total dietary nitrite intake was mostly from cold cuts and starchy foods, such as pasta and bread. Our calibration study demonstrated moderate correlations and attenuation factors for dietary nitrate and nitrite intakes assessed using the NCI DHQ compared with intake estimates based on the $24 \mathrm{HR}$.

Although nitrate and nitrite have been measured in all major foods in numerous countries ${ }^{(23,25,26,28)}$, limited efforts have been made to establish a dietary nitrate and nitrite database for the food supply in the USA and thus for $\mathrm{FFQ}^{(27-29)}$. No dietary nitrate and nitrite database was available for the FFQ used to assess dietary intake in the NIH-AARP Diet and Health cohort study. Therefore, we compiled, selected and weighted the reported literature values for foods relevant to the NCI DHQ to generate an estimate for each food item. In order to evaluate FFQbased intake estimates, we also assigned composition values to the foods reported in $24 \mathrm{HR}$ in the NIH-AARP calibration study. Average total daily intake of nitrite $(1.2 \mathrm{mg} / \mathrm{d})$ based on FFQ data among our total cohort participants was consistent with values reported in other US studies $(0.9-1.4 \mathrm{mg} / \mathrm{d})^{(16,17,63)}$. Average nitrate intake in the whole cohort was somewhat lower than previously 
Table 2 Top twenty food items contributing to total dietary nitrate intake from the FFQ and $24 \mathrm{~h}$ dietary recalls (24HR) by sex in the calibration sub-study: NIH-AARP Diet and Health Study, 1995-1996

\begin{tabular}{|c|c|c|c|c|c|c|}
\hline & \multicolumn{3}{|c|}{ FFQ } & \multicolumn{3}{|c|}{$24 \mathrm{HR}$} \\
\hline & & $\mathrm{mg} / \mathrm{d}$ & $\%$ of daily intake & & $\mathrm{mg} / \mathrm{d}$ & $\%$ of daily intake \\
\hline \multicolumn{7}{|l|}{$\overline{\text { Men }}$} \\
\hline 1. & Lettuce & $27 \cdot 4$ & 32.5 & Lettuce & 43.7 & $37 \cdot 2$ \\
\hline 2. & Cooked spinach/greens & 8.8 & 10.5 & Other vegetables* & 14.8 & $12 \cdot 6$ \\
\hline 3. & String beans & 3.6 & 4.3 & Other melon & $5 \cdot 1$ & 4.3 \\
\hline 4. & Broccoli & 3.5 & $4 \cdot 2$ & Potatoes, white & $4 \cdot 2$ & $3 \cdot 6$ \\
\hline 5. & Potatoes, white & 3.4 & 4.0 & Coleslaw/cabbage/sauerkraut & $4 \cdot 1$ & 3.5 \\
\hline 6. & Bananas & 3.2 & $3 \cdot 7$ & Cantaloupe & 4.0 & 3.4 \\
\hline 7. & Raw spinach/greens & 2.9 & $3 \cdot 4$ & Cooked spinach/greens & $3 \cdot 2$ & $2 \cdot 7$ \\
\hline 8. & Coleslaw/cabbage/sauerkraut & $2 \cdot 7$ & $3 \cdot 2$ & Bananas & $2 \cdot 6$ & $2 \cdot 2$ \\
\hline 9. & Vegetable medleys & $2 \cdot 3$ & $2 \cdot 8$ & Vegetable mixtures & 2.5 & $2 \cdot 1$ \\
\hline 10. & Other melon & $2 \cdot 3$ & $2 \cdot 7$ & Broccoli & $2 \cdot 3$ & 1.9 \\
\hline 11. & Cantaloupe & 2.0 & $2 \cdot 4$ & String beans & 1.7 & 1.4 \\
\hline 12. & Tomatoes & 1.2 & 1.4 & Vegetable medleys & 1.6 & 1.4 \\
\hline 13. & Carrots & 1.1 & 1.3 & Soups, with vegetables & 1.5 & 1.3 \\
\hline 14. & Coffee & 1.1 & 1.3 & Potatoes, fried & 1.4 & $1 \cdot 2$ \\
\hline 15. & Tomato/vegetable juice & 0.9 & $1 \cdot 1$ & Tomatoes & $1 \cdot 3$ & $1 \cdot 1$ \\
\hline 16. & Tomato sauces, with meat & 0.9 & 1.1 & Pickled vegetables/fruits & 1.3 & $1 \cdot 1$ \\
\hline 17. & Bread & 0.9 & $1 \cdot 1$ & Avocado, guacamole & 1.2 & 1.0 \\
\hline 18. & Potatoes, fried & 0.8 & 1.0 & Pasta & $1 \cdot 1$ & 0.9 \\
\hline 19. & Soups, with vegetables & 0.8 & 0.9 & Raw spinach/greens & 1.0 & 0.9 \\
\hline 20. & Peppers & 0.8 & 0.9 & Bread & 1.0 & 0.8 \\
\hline \multicolumn{7}{|c|}{ Women } \\
\hline 1. & Lettuce & $32 \cdot 1$ & $35 \cdot 0$ & Lettuce & 37.6 & $37 \cdot 1$ \\
\hline 2. & Cooked spinach/greens & $10 \cdot 4$ & 11.4 & Other vegetables* & 13.7 & 13.5 \\
\hline 3. & Broccoli & 4.4 & 4.8 & Cantaloupe & 4.4 & 4.3 \\
\hline 4. & Raw spinach/greens & 4.4 & 4.8 & Other melon & $3 \cdot 7$ & 3.6 \\
\hline 5. & String beans & 3.8 & $4 \cdot 2$ & Coleslaw/cabbage/sauerkraut & $3 \cdot 3$ & $3 \cdot 3$ \\
\hline 6. & Potatoes, white & 3.0 & $3 \cdot \overline{3}$ & Cooked spinach/greens & $3 \cdot 3$ & 3.3 \\
\hline 7. & Bananas & 3.0 & $3 \cdot 3$ & Potatoes, white & 3.0 & 3.0 \\
\hline 8. & Other melon & 2.9 & $3 \cdot 2$ & Vegetable mixtures & $2 \cdot 3$ & $2 \cdot 3$ \\
\hline 9. & Coleslaw/cabbage/sauerkraut & 2.9 & $3 \cdot 2$ & Bananas & $2 \cdot 2$ & $2 \cdot 1$ \\
\hline 10. & Cantaloupe & 2.7 & $3 \cdot 1$ & Vegetable medleys & $2 \cdot 1$ & $2 \cdot 1$ \\
\hline 11. & Vegetable medleys & $2 \cdot 1$ & $2 \cdot 3$ & Broccoli & 1.9 & 1.8 \\
\hline 12. & Carrots & 1.4 & 1.5 & Pickled vegetables/fruits & 1.6 & 1.6 \\
\hline 13. & Tomatoes & 1.3 & 1.4 & Raw spinach/greens & 1.5 & 1.5 \\
\hline 14. & Coffee & 0.9 & 1.0 & String beans & 1.5 & 1.5 \\
\hline 15. & Tomato/vegetable juice & 0.8 & 1.0 & Avocado, guacamole & 1.3 & 1.2 \\
\hline 16. & Tomato sauces, with meat & 0.8 & 0.8 & Tomatoes & $1 \cdot 3$ & 1.2 \\
\hline 17. & Bread & 0.7 & 0.8 & Strawberries & 0.9 & 0.9 \\
\hline 18. & Peppers & 0.7 & 0.8 & Soups, with vegetables & 0.8 & 0.8 \\
\hline 19. & Soups, with vegetables & 0.7 & 0.8 & Carrots & 0.8 & 0.8 \\
\hline 20. & Chicken, mixture & 0.6 & 0.7 & Pasta & 0.8 & 0.7 \\
\hline
\end{tabular}

NIH-AARP, National Institutes of Health-AARP.

${ }^{*}$ Vegetables other than those listed as line items on an FFQ, such as beets and celeries.

reported values $(100-123 \mathrm{mg} / \mathrm{d})^{(16,17,63)}$. Given that the FFQ did not capture some less frequently consumed foods that contain higher amounts of nitrate, it is possible that total daily intake levels based on FFQ data are somewhat underestimated. In our study, avocado/guacamole and pickled vegetables/fruits were among the top twenty foods contributing to dietary nitrate intake based on $24 \mathrm{HR}$ data in both men and women. However, these food items were not included in our FFQ and nitrate intake from these food items was not captured. In future studies, it is important to ensure that known major contributors of dietary nitrate and nitrite in the study population are included in dietary intake assessment tools such as FFQ.

Food items that were identified as top contributors to dietary nitrate and nitrite intakes could result from high nitrate and nitrite concentrations in foods and/or frequent consumption. For example, the amount in weight of lettuce consumed daily was relatively small; however, because of its high nitrate concentration, lettuce was the top contributor to dietary nitrate intake in our study. Meanwhile, nitrite concentrations in bread and pasta were relatively low. However, these foods were commonly consumed in relatively larger amounts and therefore identified as major contributors to dietary nitrite intake in our study. Thus, it is important to consider nitrate and nitrite concentrations in foods as well as amounts of foods commonly consumed in a study population.

Our estimates are not intended to be comprehensive in terms of all published literature regarding nitrate and nitrite in foods. Rather, the estimates we generated reflect information in the published literature that is relevant to foods consumed in the USA. High correlations between 
Table 3 Top twenty food items contributing to total dietary nitrite intake from the FFQ and $24 \mathrm{~h}$ dietary recalls (24HR) by sex in the calibration sub-study: NIH-AARP Diet and Health Study, 1995-1996

\begin{tabular}{|c|c|c|c|c|c|c|}
\hline & \multicolumn{3}{|c|}{ FFQ } & \multicolumn{3}{|c|}{$24 \mathrm{HR}$} \\
\hline & & $\mathrm{mg} / \mathrm{d}$ & $\%$ of daily intake & & $\mathrm{mg} / \mathrm{d}$ & $\%$ of daily intake \\
\hline \multicolumn{7}{|l|}{ Men } \\
\hline 1. & Cold cuts & 0.11 & 8.6 & Bread & 0.14 & 8.5 \\
\hline 2. & Bread & 0.10 & $7 \cdot 3$ & Cold cuts & 0.12 & $7 \cdot 7$ \\
\hline 3. & Pasta & 0.08 & $6 \cdot 3$ & Rice/grains & 0.10 & $6 \cdot 3$ \\
\hline 4. & Rice/grains & 0.08 & $5 \cdot 8$ & Ham & 0.09 & 5.5 \\
\hline 5. & Hot breakfast cereal & 0.07 & $5 \cdot 1$ & Pasta & 0.08 & $5 \cdot 3$ \\
\hline 6. & Apples & 0.06 & 4.4 & Hot breakfast cereal & 0.07 & 4.7 \\
\hline 7. & Ready-to-eat cereal & 0.04 & 3.3 & Ready-to-eat cereal & 0.07 & 4.2 \\
\hline 8. & Milk, non-fat/skimmed & 0.04 & 2.9 & Cakes & 0.04 & 2.8 \\
\hline 9. & Ham & 0.04 & $2 \cdot 8$ & Milk, non-fat/skimmed & 0.04 & 2.5 \\
\hline 10. & Hot dogs & 0.04 & $2 \cdot 7$ & Apples & 0.04 & $2 \cdot 3$ \\
\hline 11. & Milk, $1-2 \%$ & 0.03 & $2 \cdot 6$ & Eggs & 0.04 & $2 \cdot 3$ \\
\hline 12. & Milk, in cereal & 0.03 & 2.5 & Milk, 1-2 \% & 0.04 & $2 \cdot 3$ \\
\hline 13. & Broccoli & 0.03 & 2.5 & Hot dogs & 0.04 & $2 \cdot 2$ \\
\hline 14. & English muffin/bagel & 0.03 & 1.9 & Quick breads, donuts & 0.03 & $2 \cdot 0$ \\
\hline 15. & Corn & 0.03 & 1.9 & Other vegetables & 0.03 & 1.9 \\
\hline 16. & Eggs & 0.02 & 1.8 & Sausage & 0.03 & 1.7 \\
\hline 17. & Cakes & 0.02 & 1.5 & Pancake/waffle/French toast & 0.03 & $1 \cdot 7$ \\
\hline 18. & Soups, bean-type & 0.02 & 1.5 & English muffin/bagel & 0.03 & 1.6 \\
\hline 19. & Bananas & 0.02 & 1.5 & Potatoes, white & 0.02 & 1.4 \\
\hline 20. & Pancake/waffle/French toast & 0.02 & 1.4 & Soups with vegetables & 0.02 & 1.4 \\
\hline \multicolumn{7}{|l|}{ Women } \\
\hline 1. & Bread & 0.07 & 6.5 & Bread & 0.09 & 8.4 \\
\hline 2. & Pasta & 0.07 & 6.5 & Cold cuts & 0.06 & $5 \cdot 3$ \\
\hline 3. & Hot breakfast cereal & 0.06 & $6 \cdot 0$ & Rice/grains & 0.06 & $5 \cdot 3$ \\
\hline 4. & Rice/grains & 0.06 & $5 \cdot 8$ & Hot breakfast cereal & 0.06 & $5 \cdot 0$ \\
\hline 5. & Cold cuts & 0.05 & $5 \cdot 0$ & Ham & 0.05 & 4.5 \\
\hline 6. & Apples & 0.05 & 4.8 & Pasta & 0.05 & 4.4 \\
\hline 7. & Milk, non-fat/skimmed & 0.05 & 4.4 & Ready-to-eat cereal & 0.04 & 3.7 \\
\hline 8. & Broccoli & 0.04 & $4 \cdot 1$ & Milk, non-fat/skimmed & 0.04 & 3.5 \\
\hline 9. & Milk, 1-2 \% & 0.03 & $2 \cdot 7$ & Cakes & 0.04 & 3.4 \\
\hline 10. & Ready-to-eat cereal & 0.03 & $2 \cdot 7$ & Other vegetables & 0.03 & $2 \cdot 8$ \\
\hline 11. & Raw spinach/greens & 0.02 & $2 \cdot 3$ & Milk, $1-2 \%$ & 0.03 & 2.5 \\
\hline 12. & English muffin/bagel & 0.02 & $2 \cdot 3$ & Apples & 0.02 & $2 \cdot 2$ \\
\hline 13. & Milk, in cereal & 0.02 & $2 \cdot 3$ & Quick bread, donuts & 0.02 & $2 \cdot 2$ \\
\hline 14. & Corn & 0.02 & $2 \cdot 0$ & Egqs & 0.02 & 2.0 \\
\hline 15. & Hot dogs & 0.02 & 1.9 & English muffin/bagel & 0.02 & $2 \cdot 0$ \\
\hline 16. & $\mathrm{Ham}$ & 0.02 & 1.9 & Hot dogs & 0.02 & 1.6 \\
\hline 17. & Bananas & 0.02 & $1 \cdot 8$ & Broccoli & 0.02 & 1.5 \\
\hline 18. & Cakes & 0.02 & 1.6 & Potatoes, white & 0.02 & 1.4 \\
\hline 19. & Eggs & 0.02 & 1.6 & Crackers & 0.02 & 1.4 \\
\hline 20. & Potatoes, white & 0.01 & 1.5 & Pancake/waffle/French toast & 0.02 & 1.3 \\
\hline
\end{tabular}

NIH-AARP, National Institutes of Health-AARP.

Table 4 Estimated correlation coefficients and attenuation factors between the FFQ and true intakes based on the $24 \mathrm{~h}$ dietary recalls using a measurement error model, unadjusted and adjusted for energy intake, in the calibration sub-study: the NIH-AARP Diet and Health Study, 1995-1996

\begin{tabular}{|c|c|c|c|c|}
\hline & \multicolumn{2}{|c|}{ Correlation coefficient } & \multicolumn{2}{|c|}{ Attenuation factor } \\
\hline & Men & Women & Men & Women \\
\hline \multicolumn{5}{|l|}{ Total nitrate } \\
\hline Unadjusted & 0.53 & 0.48 & 0.49 & 0.46 \\
\hline Adjusted & 0.59 & 0.57 & 0.59 & 0.57 \\
\hline \multicolumn{5}{|l|}{ Total nitrite } \\
\hline Unadjusted & 0.45 & 0.37 & 0.32 & 0.24 \\
\hline Adjusted & 0.59 & 0.58 & 0.47 & 0.38 \\
\hline \multicolumn{5}{|l|}{ Animal nitrite } \\
\hline Unadjusted & 0.61 & 0.47 & 0.49 & 0.44 \\
\hline Adjusted & 0.64 & 0.52 & 0.56 & 0.54 \\
\hline \multicolumn{5}{|l|}{ Plant nitrite } \\
\hline Unadjusted & 0.52 & 0.48 & 0.40 & 0.30 \\
\hline Adjusted & 0.68 & 0.68 & 0.54 & 0.44 \\
\hline
\end{tabular}

$\mathrm{NIH}-\mathrm{AARP}$, National Institutes of Health-AARP. 
daily nitrate and nitrite intake estimates from processed meats using the database we developed based on a literature review and estimated daily intakes using measured nitrate and nitrite values in processed meat products indicate that our database estimates are comparable to more recent estimates of nitrate and nitrite in processed meats. Future development of a nitrate and nitrite database using a similar approach and including laboratory analysis of nitrate and nitrite contents in other food items commonly available in the USA would be ideal.

Previous analyses of the calibration study of the NCI DHQ found that correlation coefficients (not energyadjusted) between absolute intake estimates of macro- and micronutrients based on the FFQ and intake estimates based on $24 \mathrm{HR}$ ranged from 0.23 to 0.67 , and attenuation factors ranged from $0 \cdot 16$ to $0.53^{(34)}$. When adjusted for energy intake, correlation coefficients and attenuation factors improved; estimated correlation coefficients ranged from 0.36 to 0.76 , and attenuation factors ranged from 0.24 to $0 \cdot 68$. In the current analysis of dietary nitrate and nitrite intakes, findings were similar. Energy adjustment was performed in order to evaluate nutrient intake independent of total energy intake as well as to reduce measurement error ${ }^{(64)}$. Energy-adjusted correlation coefficients and attenuation factors for total nitrate, total nitrite, animal nitrite and plant nitrite between FFQ- and 24HR-based values observed in the current analysis were in a similar range to values for macro- and micronutrients in the previous analysis ${ }^{(34)}$. Using the FFQ-based energy-adjusted intake estimates, a true RR of 1.6 in the fifth quintile compared with the first quintile would be observed as 1.25 for nitrite and 1.32 for nitrate in men and 1.20 for nitrite and 1.31 for nitrate in women; whereas the observed RR would be 1.16-1.26 in men and 1.12-1.24 in women for nitrite and nitrate, respectively, if unadjusted intake estimates are used. The statistical power to detect a true RR of 1.5 using a two-sided test with a $5 \%$ significance level would be $>99 \%$ for common cancers such as colon cancer (about 4800 cases accrued over 10 years of follow-up in the NIH-AARP Diet and Health Study) but lower for less common cancers such as stomach cancer ( $42 \%$ power with about 950 cases).

One of the strengths of our study is that our dietary nitrate and nitrite database was developed primarily from previously reported values in the USA and Canada and thus is appropriate for these countries. We expanded our data resources to different countries and time periods for certain minor food items, but the contributions of nitrate and nitrite intakes from these food items to daily nitrate or nitrite intake estimates are small. Another strength is that we measured nitrate and nitrite composition of processed meats, allowing comparison of these measured values to estimates based on values derived from our literature review.

There are a few limitations as well. The contents of nitrate and nitrite in certain foods, such as processed meats, may vary across countries/regions as well as over time due to differing processing practices ${ }^{(56,57)}$. Further, the nitrate content in vegetables can vary by region ${ }^{(58)}$, because fertilizers containing ammonia or inorganic nitrates are commonly used for improving crop harvests and the extent of nitrogen fertilizer application to the crop has been associated with the level of nitrate in the plants ${ }^{(65)}$. Organically grown foods have been reported to have lower nitrate concentrations ${ }^{(65)}$. In future studies, information on study participants' consumption of organically grown produce could be collected and food-specific nitrate estimates adjusted. Moreover, data on storage time and temperature, which can decrease nitrate and increase nitrite content due to nitrate reductase enzyme activity, and food processing techniques such as peeling, pureeing, fermentation and canning ${ }^{(58,66,67)}$ were not available and thus not taken into account in our database. Peeling of vegetables can decrease nitrate content by about $30 \%$ and boiling in water may reduce nitrate by about $50 \%$; however, the degree of changes in nitrate and nitrite contents of vegetables due to processing can vary considerably by vegetable type ${ }^{(58,68)}$. Lastly, our reference instrument, the $24 \mathrm{HR}$, in the calibration study is not without error. Because the FFQ and the $24 \mathrm{HR}$ are both self-reported measurement tools, correlated errors exist in the two measurements ${ }^{(69)}$. Thus, objective reference measures such as biomarkers and data from feeding studies are ideal; however, they are usually not available in large population-based studies like ours. The $24 \mathrm{HR}$ is considered the least biased of the self-report instruments $^{(70)}$ and thus its use as a reference instrument in calibration studies evaluating FFQ is a common practice in large population-based studies.

\section{Conclusion}

In conclusion, our findings indicate that dietary nitrate and nitrite intake estimates using the NCI DHQ were moderately correlated with intake estimates based on two 24HR. Given a large number of common cancers accrued in the NIH-AARP Diet and Health Study to date, studies of these cancers and other outcomes using dietary nitrate and nitrite intake estimates assessed using the NCI DHQ are likely to be able to detect moderate elevations in risk (e.g. $\mathrm{RR} \geq 1.5$ ) in the highest $v$. lowest quantiles. Our attenuation factors should be used to de-attenuate or reduce measurement error inherent in risk estimates related to nitrate and nitrite intakes in future analyses in the NIH-AARP Diet and Health Study.

\section{Acknowledgements}

Financial support: This research was partially supported by the Intramural Research Program of the NCI, NIH, 
Department of Health and Human Services. M.I.-C. was partly supported by the Division of Intramural Research of the National Institute on Minority Health and Health Disparities, NIH. M.K.V.-B. was supported by the Cancer Prevention Fellowship at the NCI, NIH. B.A.-K. was supported by an NIH training grant (number TU2CA105666). Conflict of interest: None of the authors have conflicts of interest to disclose. Authorship: M.I.-C. contributed to data analyses, the interpretation of results and wrote the manuscript. M.K.V.-B. contributed to the interpretation of the results and writing of the manuscript. B.A.-K. contributed to the design of the study, data analyses, interpretation of the results and writing of the manuscript. A.J.C., A.F.S., F.E.T and R.S. contributed to the interpretation of the results and writing of the manuscript. M.H.W. designed the study, carried it out, and contributed to data analyses and the writing of the manuscript. All authors read and approved the final manuscript. Etbics of buman subject participation: The data collection for the NIH-AARP Diet and Health Study was approved by the NCI and the Westsat, Inc. institutional review boards. Return or completion of FFQ and 24HR was considered to be informed consent.

\section{Supplementary material}

To view supplementary material for this article, please visit http://dx.doi.org/10.1017/S1368980015003407

\section{References}

1. Chilvers C, Inskip H, Caygill C et al. (1984) A survey of dietary nitrate in well-water users. Int J Epidemiol 13, 324-331.

2. Bogovski P \& Bogovski S (1981) Animal species in which $N$-nitroso compounds induce cancer. Int J Cancer 27, 471-474.

3. International Agency for Research on Cancer (2010) IARC Monographs on the Evaluation of Carcinogenic Risks to Humans. vol. 94: Ingested Nitrate and Nitrite, and Cyanobacterial Peptide Toxins. Lyon: IARC Working Group on the Evaluation of Carcinogenic Risks to Humans.

4. Mirvish SS, Haorah J, Zhou L et al. (2003) N-Nitroso compounds in the gastrointestinal tract of rats and in the feces of mice with induced colitis or fed hot dogs or beef. Carcinogenesis 24, 595-603.

5. Vermeer IT, Pachen DM, Dallinga JW et al. (1998) Volatile $\mathrm{N}$-nitrosamine formation after intake of nitrate at the ADI level in combination with an amine-rich diet. Environ Health Perspect 106, 459-463.

6. Mirvish SS (1995) Role of $N$-nitroso compounds (NOC) and $\mathrm{N}$-nitrosation in etiology of gastric, esophageal, nasopharyngeal and bladder cancer and contribution to cancer of known exposures to NOC. Cancer Lett 93, 17-48.

7. Zhou L, Anwar MM, Zahid M et al. (2014) Urinary excretion of $\mathrm{N}$-nitroso compounds in rats fed sodium nitrite and/or hot dogs. Chem Res Toxicol 27, 1669-1674.

8. Mirvish SS, Grandjean AC, Reimers KJ et al. (1995) Dosing time with ascorbic acid and nitrate, gum and tobacco chewing, fasting, and other factors affecting $N$-nitrosoproline formation in healthy subjects taking proline with a standard meal. Cancer Epidemiol Biomarkers Prev 4, 775-782.
9. Mirvish SS, Grandjean AC, Reimers KJ et al. (1998) Effect of ascorbic acid dose taken with a meal on nitrosoproline excretion in subjects ingesting nitrate and proline. Nutr Cancer 31, 106-110.

10. Keszei AP, Goldbohm RA, Schouten LJ et al. (2013) Dietary $\mathrm{N}$-nitroso compounds, endogenous nitrosation, and the risk of esophageal and gastric cancer subtypes in the Netherlands Cohort Study. Am J Clin Nutr 97, 135-146.

11. Loh YH, Jakszyn P, Luben RN et al. (2011) N-Nitroso compounds and cancer incidence: the European Prospective Investigation into Cancer and Nutrition (EPIC)-Norfolk Study. Am J Clin Nutr 93, 1053-1061.

12. Dellavalle CT, Xiao Q, Yang G et al. (2014) Dietary nitrate and nitrite intake and risk of colorectal cancer in the Shanghai Women's Health Study. Int J Cancer 132, 2917-2926.

13. van Loon AJ, Botterweck AA, Goldbohm RA et al. (1998) Intake of nitrate and nitrite and the risk of gastric cancer: a prospective cohort study. Br J Cancer 78, 129-135.

14. Knekt P, Jarvinen R, Dich J et al. (1999) Risk of colorectal and other gastro-intestinal cancers after exposure to nitrate, nitrite and $\mathrm{N}$-nitroso compounds: a follow-up study. Int $\mathrm{J}$ Cancer 80, 852-856.

15. Aschebrook-Kilfoy B, Ward MH, Gierach GL et al. (2012) Epithelial ovarian cancer and exposure to dietary nitrate and nitrite in the NIH-AARP Diet and Health Study. EurJ Cancer Prev 21, 65-72.

16. Aschebrook-Kilfoy B, Shu XO, Gao YT et al. (2013) Thyroid cancer risk and dietary nitrate and nitrite intake in the Shanghai Women's Health Study. Int J Cancer 132, 897-904.

17. Inoue-Choi M, Jones RR, Anderson KE et al. (2015) Nitrate and nitrite ingestion and risk of ovarian cancer among postmenopausal women in Iowa. Int J Cancer 137, 173-182.

18. Cross AJ, Freedman ND, Ren J et al. (2011) Meat consumption and risk of esophageal and gastric cancer in a large prospective study. Am J Gastroenterol 106, 432-442.

19. Ferrucci LM, Sinha R, Graubard BI et al. (2009) Dietary meat intake in relation to colorectal adenoma in asymptomatic women. Am J Gastroenterol 104, 1231-1240.

20. Dubrow R, Darefsky AS, Park Y et al. (2010) Dietary components related to $N$-nitroso compound formation: a prospective study of adult glioma. Cancer Epidemiol Biomarkers Prev 19, 1709-1722.

21. Aschebrook-Kilfoy B, Cross AJ, Stolzenberg-Solomon RZ et al. (2011) Pancreatic cancer and exposure to dietary nitrate and nitrite in the NIH-AARP Diet and Health Study. Am J Epidemiol 174, 305-315.

22. Dellavalle CT, Daniel CR, Aschebrook-Kilfoy B et al. (2013) Dietary intake of nitrate and nitrite and risk of renal cell carcinoma in the NIH-AARP Diet and Health Study. Br J Cancer 108, 205-212.

23. Jakszyn P, Agudo A, Ibanez R et al. (2004) Development of a food database of nitrosamines, heterocyclic amines, and polycyclic aromatic hydrocarbons. J Nutr 134, 2011-2014.

24. van Loon AJ, Botterweck AA, Goldbohm RA et al. (1997) Nitrate intake and gastric cancer risk: results from the Netherlands cohort study. Cancer Lett 114, 259-261.

25. Cornee J, Lairon D, Velema J et al. (1992) An estimate of nitrate, nitrite, and $\mathrm{N}$-nitrosodimethylamine concentrations in French food products or food groups. Sci Aliment 12, 155-197.

26. Ysart G, Miller P, Barrett G et al. (1999) Dietary exposures to nitrate in the UK. Food Addit Contam 16, 521-532.

27. Griesenbeck JS, Steck MD, Huber JC Jr, et al. (2009) Development of estimates of dietary nitrates, nitrites, and nitrosamines for use with the Short Willett Food Frequency Questionnaire. Nutr J 8, 16.

28. Choi BC (1985) $\mathrm{N}$-Nitroso compounds and human cancer. A molecular epidemiologic approach. Am J Epidemiol 121, $737-743$. 
29. Mayne ST, Risch HA, Dubrow R et al. (2001) Nutrient intake and risk of subtypes of esophageal and gastric cancer. Cancer Epidemiol Biomarkers Prev 10, 1055-1062.

30. Schatzkin A, Subar AF, Thompson FE et al. (2001) Design and serendipity in establishing a large cohort with wide dietary intake distributions: the National Institutes of Health-American Association of Retired Persons Diet and Health Study. Am J Epidemiol 154, 1119-1125.

31. Gierach GL, Freedman ND, Andaya A et al. (2012) Coffee intake and breast cancer risk in the NIH-AARP diet and health study cohort. Int J Cancer 131, 452-460.

32. Subar AF, Midthune D, Kulldorff M et al. (2000) Evaluation of alternative approaches to assign nutrient values to food groups in food frequency questionnaires. Am J Epidemiol 152, 279-286.

33. Friday JE \& Bowman SA (2014) MyPyramid Equivalents Database for USDA Survey Food Codes, 1994-2002, Version 1.O. Beltsville, MD: US Department of Agriculture, Agricultural Research Service, Community Nutrition Research Group.

34. Thompson FE, Kipnis V, Midthune D et al. (2008) Performance of a food-frequency questionnaire in the US NIH-AARP (National Institutes of Health-American Association of Retired Persons) Diet and Health Study. Public Health Nutr 11, 183-195.

35. Achtzehn MK \& Hawat H (1969) Die Anreicherung von Nitrat in den Gemüsenarten - eine Möglichkeit der Nitratintoxikation bei Säuglingen. Nabrung 13, 667-676.

36. Gangolli SD, van den Brandt PA, Feron VJ et al. (1994) Nitrate, nitrite and $N$-nitroso compounds. Eur J Pharmacol 292, 1-38.

37. Harada M, Ishiwata H, Nakamura Y et al. (1975) Studies on in vitro formation of nitroso compounds. I. Changes of nitrite and nitrate concentrations in human saliva after ingestion of salted Chinese cabbage. J Food Hyg Soc Jpn 16, 11-18.

38. Howe GR, Harrison L \& Jain M (1986) A short diet history for assessing dietary exposure to $N$-nitrosamines in epidemiologic studies. Am J Epidemiol 124, 595-602.

39. Jackson WA, Steel JS \& Boswell VR (1967) Nitrates in edible vegetables and vegetable products. Proc Am Soc Hort Sci 90, 349-352.

40. Lee CY (1972) Nitrogen compounds in vegetable foods. In Environmental Contaminants in Foods, Proceedings of Sixth Annual Symposium, November 18, 1971. Special Report no. 8, pp. 8-9. Geneva: New York State Agricultural Experiment Station.

41. Ministry of Agriculture, Fisheries and Food (1998) 1998-1997 Total Diet Study Nitrate and Nitrite. UK Food Surveillance Information Sheet no. 163. London: MAFF.

42. Maynard DN \& Barker AV (1972) Nitrate content of vegetable crops. HortScience 7, 224-226.

43. Meah MN, Harrison N \& Davies A (1994) Nitrate and nitrite in foods and the diet. Food Addit Contam 11, 519-532.

44. Menard C, Heraud F, Volatier JL et al. (2008) Assessment of dietary exposure of nitrate and nitrite in France. Food Addit Contam Part A Chem Anal Control Expo Risk Assess 25, 971-988.

45. National Research Council, Committee on Nitrite and Alternative Curing Agents in Food (1981) The Health Effects of Nitrate, Nitrite and N-Nitroso Compounds, pp. 5-28. Washington, DC: National Academy of Sciences.

46. Panalaks T, Iyengar JR \& Sen NP (1973) Nitrate, nitrite, and dimethylnitrosamine in cured meat products. J Assoc Off Anal Chem 56, 621-625.

47. Panalaks T, Iyengar JR, Donaldson BA et al. (1974) Further survey of cured meat products for volatile $N$-nitrosamines. J Assoc Off Anal Chem 57, 806-812.

48. Peterson A \& Stoltz S (1999) Nitrate and nitrite in vegetable on the Danish market: content and intake. Food Addit Contam 16, 291-299.
49. Pogoda JM \& Preston-Martin S (2001) Maternal cured meat consumption during pregnancy and risk of paediatric brain tumour in offspring: potentially harmful levels of intake. Public Health Nutr 4, 183-189.

50. Rooma MI (1971) Content of nitrates, nitrites, and hydroxylamines in food products. Gig Sanit 36, 46-50.

51. Selenka F \& Brand-Grimm D (1976) Nitrate and nitrite in human food calculation of the daily intake and its range. Zentralbl Bakteriol Orig B 162, 449-466.

52. Shahlaei A, Ansari NA \& Dehkordie FS (2007) Evaluation of nitrate and nitrite content of Iran southern vegetable during spring and winter of 2006. Asian J Plant Sci 6, 1197-1203.

53. Siciliano J, Krulick S, Heisler EG et al. (1975) Nitrate and nitrite content of some fresh and processed market vegetables. J Agric Food Chem 23, 461-464.

54. Susin J, Kmecl V \& Gregorcic A (2006) A survey of nitrate and nitrite content of fruit and vegetables grown in Slovenia during 1996-2002. Food Addit Contam 23, 385-390.

55. Thomson BM, Nokes CJ \& Cressey PJ (2007) Intake and risk assessment of nitrate and nitrite from New Zealand foods and drinking water. Food Addit Contam 24, 113-121.

56. White JW Jr (1975) Relative significance of dietary sources of nitrate and nitrite. J Agric Food Chem 23, 886-891.

57. Honikel KO (2008) The use and control of nitrate and nitrite for the processing of meat products. Meat Sci 78, 68-76.

58. European Food Safety Authority (2008) Nitrate in vegetables - Scientific opinion of the panel on contaminants in the food chain. EFSA J 689, 1-79.

59. Sinha R, Cross A, Curtin J et al. (2005) Development of a food frequency questionnaire module and databases for compounds in cooked and processed meats. Mol Nutr Food Res 49, 648-655.

60. Ward MH, Cross AJ, Divan H et al. (2007) Processed meat intake, CYP2A6 activity and risk of colorectal adenoma. Carcinogenesis 28, 1210-1216.

61. Kipnis V, Midthune D, Freedman LS et al. (2001) Empirical evidence of correlated biases in dietary assessment instruments and its implications. Am J Epidemiol 153, 394-403.

62. Willett WC, Howe GR \& Kushi LH (1997) Adjustment for total energy intake in epidemiologic studies. Am J Clin Nutr 65, 1220S-1228S.

63. Kilfoy BA, Zhang Y, Park Y et al. (2010) Dietary nitrate and nitrite and the risk of thyroid cancer in the NIH-AARP Diet and Health Study. Int J Cancer 129, 160-172.

64. Willett W (2001) Commentary: Dietary diaries versus food frequency questionnaires - a case of undigestible data. Int J Epidemiol 30, 317-319.

65. Anjana SU \& Iqbal M (2007) Nitrate accumulation in plants, factors affecting the process, and human health implications. A review. Agron Sustain Dev 27, 45-57.

66. Chung JC, Chou SS \& Hwang DF (2004) Changes in nitrate and nitrite content of four vegetables during storage at refrigerated and ambient temperatures. Food Addit Contam 21, 317-322.

67. Schuster BE \& Lee K (1987) Nitrate and nitrite methods of analysis and levels in raw carrots, processed carrots and in selected vegetables and grain products. J Food Sci 52, $1632-1636$.

68. Leszczynska T, Filipiak-Florkiewicz A, Cieslik E et al. (2009) Effects of some processing methods on nitrate and nitrite changes in cruciferous vegetables. J Food Compost Anal 22, 315-321.

69. Kaaks R, Riboli E, Esteve J et al. (1994) Estimating the accuracy of dietary questionnaire assessments: validation in terms of structural equation models. Stat Med 13, 127-142.

70. National Cancer Institute (n.d.) Dietary Assessment Primer. http://dietassessmentprimer.cancer.gov/ (accessed September 2015). 